\title{
Global public goods and health
}

\author{
Richard D. Smith ${ }^{1}$
}

Health improvement requires collective as well as individual action, and the health of poor populations in particular requires collective action between countries as well as within them. Initiatives such as the Global Fund to Fight AIDS, Tuberculosis and Malaria reflect a growing awareness of this fact. However, initiating, organizing and financing collective actions for health at the global level presents a challenge to existing international organizations (1).

The concept of "global public goods" (GPGs) suggests one possible framework for considering these issues (2). In this expression, "goods" encompass a range of physical commodities (such as bread, books and shoes) but includes services (such as security, information and travel), distinguishing between private and public goods. Most goods are "private" in the sense that their consumption can be withheld until a payment is made in exchange for them, and once consumed they cannot be consumed again. In contrast, once "public" goods are provided no one can be excluded from consuming them (they are non-excludable), and one person's consumption of them does not prevent anyone else's (they are non-rival in consumption) (3). For example, no one in a population can be excluded from benefiting from a reduction in risk of infectious disease when its incidence is reduced, and one person benefiting from this reduction in risk does not prevent anyone else from benefiting from it as well.

Global public goods are goods of this kind whose benefits cross borders and are global in scope. For example, reductions in carbon dioxide emissions will slow global warming. It will be impossible to exclude any country from benefiting from this, and each country will benefit without preventing another from doing so. Similarly, the eradication of infectious diseases of global scope, such as smallpox or polio, provides a benefit from which no country is excluded, and from which all countries will benefit without detriment to others.

However, these attributes of public goods give rise to a paradox: although there is significant benefit to be gained from them by many people, there is no commercial incentive for producing them, since enjoyment cannot be made conditional on payment. With national public goods, the government therefore intervenes either financially, through such mechanisms as taxation or licensing, or with direct provision. But for global public goods this is harder to do, because no global government exists to ensure that they are produced and paid for. The central issue for health-related GPGs is how best to ensure that the collective action necessary for health is taken at the international level.

Globalization of travel, changes in technology, and the liberalization of trade all affect health. Communicable diseases spread more rapidly, often in drug-resistant form (4), environmental degradation reduces access to clean air and water, and knowledge of traditional and modern health technologies is increasingly patented and thus made artificially excludable (5). However, discussion of GPGs to date has typically been broad-based and multisectoral (for instance on the environment, international security and trade agreements), and most of the discussion within the health sector has been focused on medical technologies $(3,6,7)$.

This has left many questions unanswered (8). For example, is health itself a GPG? To what extent does my (national) health depend on your (national) health? How many of the actions necessary to global health - communicable disease control, generation and dissemination of medical knowledge, public health infrastructure - constitute GPGs? What contribution can the GPG concept make to fulfilling these needs? Is international financing for these GPGs best coordinated through voluntary contributions, global taxation systems, or market-based mechanisms? Does the concept of GPGs undermine or support concepts of equity and human rights?

The first large-scale study of the application of the GPG concept to the health sector examines questions such as these, and has just been published (8). The study finds that, while the concept has important limitations, for some areas of health work it can offer guidance in the financing and provision of global health programmes. In these areas it provides a framework for collective action at the global level, demonstrates the advantages for the rich in helping the poor, and provides a rationale for industrialized countries to use national health budgets to complement traditional aid (as seen in the Polio Eradication Initiative (9)). Overall, the GPG concept will be increasingly important as a rationale and a guide for public health work in an era of globalization.

1. Drager N, Beaglehole R. Globalization: changing the public health landscape. Bulletin of the World Health Organization 2001;79:803.

2. Kaul I, Faust M. Global public goods and health: taking the agenda forward. Bulletin of the World Health Organization 2001;79:869-74.

3. Kaul I, Grunberg I, Stern MA, editors. Global public goods: international cooperation in the 21st century. New York: Oxford University Press; 1999.

4. Smith RD, Coast J. Antimicrobial resistance: a global response. Bulletin of the World Health Organization 2002;80:126-33.

5. Thorsteinsdóttir $H$, Daar A, Smith RD, Singer P. Genomics - a global public good? Lancet 2003;361:891-2.

6. Kaul I, Conceição P, Le Goulven K, Mendoza RU, editors. Providing global public goods: managing globalization. New York: Oxford University Press; 2003.

7. Macroeconomics and health: investing in health for economic development. Report of the Commission on Macroeconomics and Health. Geneva: World Health Organization; 2001.

8. Smith RD, Beaglehole R, Woodward D, Drager N, editors. Global public goods for health: a health economic and public health perspective. Oxford: Oxford University Press; 2003.

9. Aylward B, Acharya A, England S, et al. Achieving global health goals: the politics and economics of polio eradication. Lancet (forthcoming).

\footnotetext{
${ }^{1}$ Senior Lecturer in Health Economics, University of East Anglia, Norwich NR4 7TJ, England (email Richard.Smith@uea.ac.uk).
} 